ТЕМКИН Владимир Леонидович - аспирант Института права и национальной безопасности Российской академии народного хозяйства и государственной службы при Президенте РФ (127473, Россия, г. Москва, ул. Достоевского, 1/21, temkinmir@mail.ru)

СИНИЦЫН Игорь Михайлович - ученый секретарь Центра исследования проблем безопасности Российской академии наук (117335, Россия, г. Москва, ул. Гарибальди, 21б, IM_9380752@таil.ru)

\title{
К ВОПРОСУ ИНСТИТУЦИОНАЛЬНОГО ОБЕСПЕЧЕНИЯ ГОСУДАРСТВЕННОЙ МОЛОДЕЖНОЙ ПОЛИТИКИ И ЕЕ НОРМАТИВНО-ПРАВОВОГО ОБОСНОВАНИЯ В РОССИИ И МИРЕ
}

\begin{abstract}
Аннотация. В публикации рассмотрены некоторые актуальные вопросы обеспечения государственной молодежной политики в Российской Федерации, кратко показан опыт иностранных государств. Авторы обозначают необходимость принятия закона «О молодежи» и важность институционализации государственной молодежной политики.
\end{abstract}

Ключевые слова: государственная молодежная политика, институционализация, молодежь, законодательство, государство, общество

$\mathrm{H}$ а встрече с представителями общественных молодежных объединений и волонтерских организаций после инаугурации в мае 2018 г. вновь избранный президент России В.В. Путин высоко оценил роль и место молодежи в государственном управлении и строительстве обновленной России: «Вижу... залог преемственности нашего стратегического курса и устойчивого развития России. Рассчитываю здесь на новые идеи и подходы, на дерзновенность нашей молодежи, на ее способность стать настоящими лидерами перемен. На то, что молодые люди будут верны ценностям правды и справедливости, которые через всю свою жизнь пронесли наши старшие поколения, их знания, закалка, мудрость, опыт наставников, безусловно, будут востребованы» 1 .

Вместе с тем вопрос участия молодежи, институционализации государственной молодежной политики (ГМП) в России, по мнению авторов, требует большего внимания со стороны государственных органов, т.к. современное состояние не позволяет определить четкие границы прав, обязанностей и ответственности государства и его институтов, а также общества в этой области. В развитии ГМП Россия отстала от современного мира почти на два десятка лет.

Опыт западных государств свидетельствует, что уже с конца 70-х гг. в связи с резко возросшей безработицей западные государства начали разрабатывать специальное законодательство в отношении молодого поколения, т.к. прежние механизмы социальной адаптации молодежи перестали работать, а уровень ее образования не соответствовал технологическим и экономическим потребностям.

Юридические нормы, регламентирующие положение молодежи, традиционно включались в законодательные акты по социальному обеспечению, образованию, трудовым отношениям и т.п. Законодательное закрепление прав молодежи в 1980-1990-х гг. стало мировой тенденцией в странах Запада. Так, в

\footnotetext{
${ }^{1}$ Владимир Путин пообщался с волонтерами после инаугурации. - Российская газета - Неделя. № 99(7562). 10.05.2018. Доступ: https://rg.ru/2018/05/10/vladimir-putin-molodezh-dolzhna-stat-lideromperemen.html (проверено 30.08.2019).
} 
США с середины 1970-х гг. социальная помощь, затрагивавшая интересы молодого поколения, оказывалась посредством 160 федеральных программ, которые действовали на основании одобренных конгрессом законодательных актов.

В США в 1980 г. президентская инициатива об образовании и трудоустройстве молодежи ставила целью повышение возможностей трудоустройства наиболее нуждающихся молодых людей; на основе Акта о социальном обеспечении (поправка 1978 г.) выплачивались пособия на детей до 18 лет и студентов до 21 года из неполных семей, а в некоторых штатах - из семей безработных. В 1970-1980-х гг. в США утверждались программы помощи молодежи из коренного индейского населения, убежавшим из дома подросткам, молодым инвалидам, сиротам и т.п.

По акту об уравнивании возможностей для получения начального и среднего образования около 5,6 млн детей и подростков в 1990-х гг. получали государственную поддержку. Важно отметить, что законы США жестко регламентируют порядок расходования средств и категорию получателей помощи (социальный статус, возраст, уровень доходов семьи и т.п.).

В большинстве стран Запада институционализировано ювенальное законодательство и ювенальная система, которые включают специальные суды для несовершеннолетних, исправительные учреждения, разнообразные воспитательные и реабилитационные службы.

Развитие западноевропейского законодательства в сфере молодежи получило развитие в связи с интенсивными интеграционными процессами, такими как создание единого рынка, необходимость согласованности в социальной политике, которые требовали свободного перемещения капиталов и рабочей силы, а также выравнивания правовых возможностей и социальных гарантий молодежи [Чирун 2009].

Программа по обмену студентами и преподавателями «Эразмус» 1 , которая гарантировала возможность обучения в любой стране Общего рынка, подтолкнула Швецию к принятию законов, изменивших структуру высшего образования и предоставивших студентам право на получение субсидии для обучения в западноевропейских университетах. Страны Южной Европы, существенно отставшие в этом отношении от общеевропейского уровня, вынуждены были проделать весьма существенную работу.

Интересным представляется опыт Испании, которая за короткое время смогла уйти от авторитарных методов к демократическим, от единственной и монопольной молодежной организации - к широкому плюрализму в молодежной среде, создала систему органов, отвечающих за ГМП [Кочетков 2004].

В 1983-1989 гг. Испания приняла ряд законодательных актов, регулирующих ГМП. Законодательная база подкреплялась источниками финансирования.

В странах Западной Европы действовали различные социальные программы. Во Франции - программа производственного обучения и альтернативной профессиональной подготовки для молодежи, в Великобритании - программа «Возможности для молодежи» (1984), в Финляндии - Акт о работе молодежи (1997).

Закон ФРГ о помощи детям и молодежи от 26.06.1990 г. является правовой основой защиты прав и интересов молодежи и детей, четко определяет задачи работы с молодежью.

Государство обеспечивает прямой контакт с молодежью, ее участие в общественной жизни. Однако для эффективного применения ГМП необходима его

\footnotetext{
1 Эразмус (англ. - Erasmus) - некоммерческая программа Европейского союза по обмену студентами и преподавателями между университетами стран - членов Евросоюза, а также Исландии, Лихтенштейна, Македонии, Норвегии, Турции.
} 
институционализация, финансирование. Перед странами Европы стоит задача увеличения финансирования молодежных программ. Например, в России действует система молодежных советов при различных органах исполнительной, законодательной власти и местного самоуправления, в которых, к сожалению, не хватает финансировании для выполнения возложенных задач в полном объеме.

В Европе обязательства по финансированию молодежной политики переносятся на региональный и местный уровни. Большая роль отводится внебюджетному финансированию. Россия на современном этапе сталкивается с ситуацией, когда получение грантов неразрывно связано с системой «откатов», что приводит к деградации данного института в России.

Регулирование ГМП в Европе ведется на государственном, региональном и местном уровнях. Государство регулирует вопросы демографии, образовательный процесс, трудоустройство. Правительственные органы в основном выполняют такие функции, как:

- государственная поддержка детей и молодежи в различных сферах;

- координация государственных программ поддержки трудовой занятости детей и молодежи;

- изучение и исследование проблем молодежи;

- образовательно-просветительская деятельность.

Многие страны придерживаются принципа межведомственной координации и реализации ГМП. Иной формат организации ГМП действует в Японии, где функционал каждого органа имеет четко определенные полномочия и установленную сферу ответственности, действуя при координации Комитета по поддержке развития молодежи.

Наблюдается тенденция смещения ГМП с федерального на региональный и местный уровни. Так, в Испании на местном и региональном уровнях действуют специальные управления, в Германии - ведомства по делам молодежи; функциями распределения бюджетных средств наделены отделы и комиссии по делам молодежи, входящие в состав муниципалитетов и коммунальных советов. Они осуществляют организацию работы с молодежью на местах (досуг, спорт, профориентация). В ФРГ приоритет по работе с молодежью отдан «свободным носителям», в случае их отсутствия создаются соответствующие государственные учреждения. Принята конкурсная основа финансирования.

Таким образом, государственные органы имеют возможность регулировать фундамент, на котором основана работа с молодежью, устанавливать приоритеты ГМП, распределять ресурсы на ГМП.

В вопросах реализации ГМП Россия отстала от западных стран на 15-20 лет. Безусловно, разрушающее влияние оказали события 1990-х гг., последствия которых пришлось решать в нулевых, после чего случился мировой финансовый кризис, введены санкции, усилилась напряженность в международных отношениях. Все эти факты вынуждают российскую власть делать акцент на иных сферах, но нельзя забывать, что «потерянное молодое поколение» несет в своем потенциале угрозу, сопоставимую по разрушительности воздействия с поражением в войне. Необходимо помнить, что именно молодежь выступала авангардом революционных событий в истории.

Основываясь на глобальных тенденциях, правительство РФ разработало Основы государственной молодежной политики РФ на период до 2025 года 1 (далее - Основы), т.к. стратегическими преимуществами обладают государства, эффективно использующие потенциал молодежи. Это подтверждается следую-

\footnotetext{
${ }^{1}$ Распоряжение Правительства РФ от 29.11.2014 N 2403-р «Об утверждении Основ государственной молодежной политики Российской Федерации на период до 2025 года». Доступ: https://legalacts.ru/ doc/rasporjazhenie-pravitelstva-rf-ot-29112014-n-2403-r/ (проверено 30.08.2019).
} 
щим: «во-первых, в любые исторические периоды молодежь выступает в качестве движущей силы развития общества в целом, то же самое мы можем сказать и о современной молодежи; во-вторых, в современном российском обществе происходит процесс поляризации среди молодежи, что требует более глубокого изучения позиции молодых людей, в частности изучения ценностей молодежи, мотивов, которые лежат в основе их поведенческой активности; в-третьих, молодежи присуща динамичность с точки зрения подверженности влиянию политических и экономических факторов» [Бадмаева и др. 2016].

При рассмотрении Основ обращает на себя внимание отсутствие единого возрастного индикатора на территории РФ, в рамках которого могут использоваться термины (например, «молодежь» - эта группа включает лиц в возрасте от 14 до 30 лет, а в некоторых случаях, определенных нормативными правовыми актами РФ и субъектов РФ, - до 35 и более лет).

Далее, в общем положении Основ делается акцент на особой роли молодежи в социально-экономическом развитии страны, на ее мобильности и инновационном потенциале. Отмечена необходимость развития ГМП.

Приоритетными задачами названы воспитательная роль семьи, общества и государства, развитие гражданского общества, участие молодежи в формировании общественных благ; стратегическим приоритетом ГМП названо создание условий для формирования личности гармоничной, постоянно совершенствующейся, эрудированной, конкурентоспособной, неравнодушной, обладающей прочным нравственным стержнем, способной при этом адаптироваться к меняющимся условиям и восприимчивой к новым созидательным идеям.

Также отмечены определенные успехи в данной сфере, такие как уменьшение смертности среди молодежи, усиление стремления к ведению здорового образа жизни, снижение уровня молодежной безработицы и преступности (в т.ч. среди несовершеннолетних), мировое лидерство по числу специалистов с высшим образованием.

Отмечены и негативные факторы, влияющие на развитие молодежи: деструктивное информационное воздействие на молодежь (вследствие чего повышается агрессивность, национальная и религиозная нетерпимость, социальное напряжение), снижение численности молодежи вследствие демографических проблем прошлых лет (что может оказать влияние на социально-экономическое развитие страны, привести к убыли населения, сокращению трудовых ресурсов, росту пенсионной нагрузки, что подтверждается недавно реализованной пенсионной реформой, и ослаблению обороноспособности РФ).

К основным задачам относится воспитание патриотично настроенной молодежи с независимым мышлением, обладающей созидательным мировоззрением, профессиональными знаниями, демонстрирующей высокую культуру, в т.ч. культуру межнационального общения, ответственность и способность принимать самостоятельные решения, нацеленные на повышение благосостояния страны, народа и своей семьи. Государство и общество должны создавать базовые условия для полноценной самореализации молодежи в социально-экономической и общественно-политической сферах жизни России.

ГМП направлена на улучшение социального и экономического положения российской молодежи, увеличение ее вовлеченности в экономическую и социальную жизнь государства.

Основными ее принципами являются взаимная ответственность и партнерство государства, общества и молодежи; поддержка молодежи во всех сферах жизни общества; повышение эффективности использования информационных ресурсов и инфраструктуры и укрепление механизмов правового регулирования. 
Целями ГМП являются совершенствование правовых, социально-экономических и организационных условий для успешной самореализации молодежи, направленной на раскрытие ее потенциала для дальнейшего развития РФ, a также содействие успешной интеграции молодежи в общество и повышению ее роли в жизни страны.

Для достижения поставленных целей и задач необходимо выделение и рациональное расходование значительных бюджетных средств, однако, несмотря на прилагаемые усилия, в ГМП требуется принятие комплекса решений по нормативному и ресурсному обеспечению.

Отдельно важно отметить следующие приоритетные задачи ГМП в соответствии с Основами:

- формирование системы ценностей молодежи;

- развитие просветительской работы с молодежью, инновационных образовательных и воспитательных технологий, а также создание условий для самообразования молодежи;

- формирование ценностей здорового образа жизни, создание условий для физического развития молодежи, формирование экологической культуры, а также повышение уровня культуры безопасности жизнедеятельности молодежи;

- создание условий для реализации потенциала молодежи в социально-экономической сфере, а также внедрение технологий социального лифта;

- создание благоприятных условий для молодых семей с целью повышения рождаемости, формирование ценностей семейной культуры и образа успешной молодой семьи, оказание всесторонней поддержки молодым семьям;

- формирование информационного поля, благоприятного для развития молодежи, интенсификация механизмов обратной связи между государственными структурами, общественными объединениями и молодежью, а также повышение эффективности использования информационной инфраструктуры в целях патриотического и гражданского воспитания молодежи 1 .

В Основах отражены некоторые аспекты международного взаимодействия в молодежной сфере. Это:

- вовлечение молодежи в процесс развития и укрепления ЕЭС, СНГ;

- привлечение перспективной зарубежной молодежи к социально-экономической жизни России;

- поддержка участия российской молодежи и молодежных объединений на международном уровне;

- реализация программ двусторонних обменов, развитие сотрудничества с молодежными организациями соотечественников за рубежом.

Можно резюмировать, что данные положения носят в целом декларативный характер. Отсутствует необходимая нормативно-правовая база, конкретизация указанных в Основах направлений ГМП и институционализация ГМП в России для их успешной реализации.

Авторы предлагают дополнить определение государственной молодежной политики, данное в Основах, следующими положениями: ГМП - общенациональное стратегическое направление Российской Федерации, включающее в себя систему мер нормативно-правового, финансово-экономического, организационно-управленческого, информационно-аналитического, кадрового и научного характера, реализуемых на основе взаимодействия с институтами

\footnotetext{
1 Определены основы молодежной политики России на период до 2025 года. Доступ: https:// www.consultant.ru/law/hotdocs/39133.html/?utm_campaign=hotdocs\&utm_source=google.adwords\&utm_ medium $=$ cpc\&utm_content $=1 \&$ gclid $=$ EAIaIQobC $\overline{C h M I m a q M 6 s O C 2 w I V k s m y C h 1 X x g 44 E A M Y A S A A E g K \bar{p}}$ SfD_BwE (проверено 30.08.2019).
} 
гражданского общества и гражданами, активного межведомственного взаимодействия, направленных на решение проблем молодежи; гражданско-патриотическое и духовно-нравственное воспитание, создание возможностей для эффективной самореализации молодежи в целях достижения устойчивого социально-экономического развития, глобальной конкурентоспособности, национальной безопасности страны, преемственности поколений, а также упрочения ее позиций на мировой арене и активного включения в международные молодежные структуры и проекты.

Новеллой Основ, как представляется, должен стать блок «Участие российской молодежи в международных молодежных структурах и проектах». Необходимо отходить от исключительной ориентации молодого поколения на ЕЭС и СНГ, отойти от позиций изоляционизма. В указанный блок могут войти:

- участие российской молодежи в международном молодежном движении;

- участие в международных молодежных структурах;

- взаимодействие с иностранными молодежными структурами;

- участие в иностранных молодежных структурах;

- участие в международных молодежных проектах;

- участие в иностранных молодежных проектах;

- участие иностранной молодежи в деятельности российских молодежных структур;

- участие в российских молодежных проектах;

- финансирование молодежных международных проектов с участием российской молодежи;

- финансирование российских молодежных проектов с участием иностранной молодежи;

- поддержка волонтерского движения.

В России имеются наработанные эффективные практики работы с молодежью ${ }^{1}$.

ГМП в России урегулирована частично, в основном законодательными актами субъектов РФ. Этот вопрос требует детальной проработки. Отсутствие институционализации ГМП может привести к нарушению баланса преемственности поколений в ближайшей перспективе ${ }^{2}$.

Считаем необходимым разработать и принять в России закон «О молодежи», который позволит:

- определить сферу молодежной политики и дать дополнительные правовые основания органам, занимающимся реализацией молодежной политики;

- создать единое правовое пространство молодежной политики в стране;

- распределить полномочия и ответственность между федеральными и региональными органами власти, местным самоуправлением;

- запустить вопрос разработки ювенального законодательства;

- разработать терминологическую базу 3 .

Институционализация ГМП придаст отрасли четкие контуры, обозначит приоритеты и перспективы развития [Ценностные ориентации... 2017].

Институционализация ГМП России заключается в 1) разработке и принятии закона «О молодежи» (нормативно-правовое обеспечение); 2) введении в структуре органов государственной власти специального уполномоченного по делам молодежи в статусе помощника Президента РФ; 3) наделении Росмолодежи и

\footnotetext{
${ }^{1}$ Семья и любовь: в ТАСС презентовали исследование о ценностях и настроениях современной российской молодежи. Доступ: https://guu.ru/news_ru/39376 (проверено 30.08.2019).

2 Там же.

3 Там же.
} 
Россотрудничества функциями межведомственной координации федеральных органов исполнительной власти.

Схематично институционализация ГМП может выглядеть следующим образом (см. рис. 1).

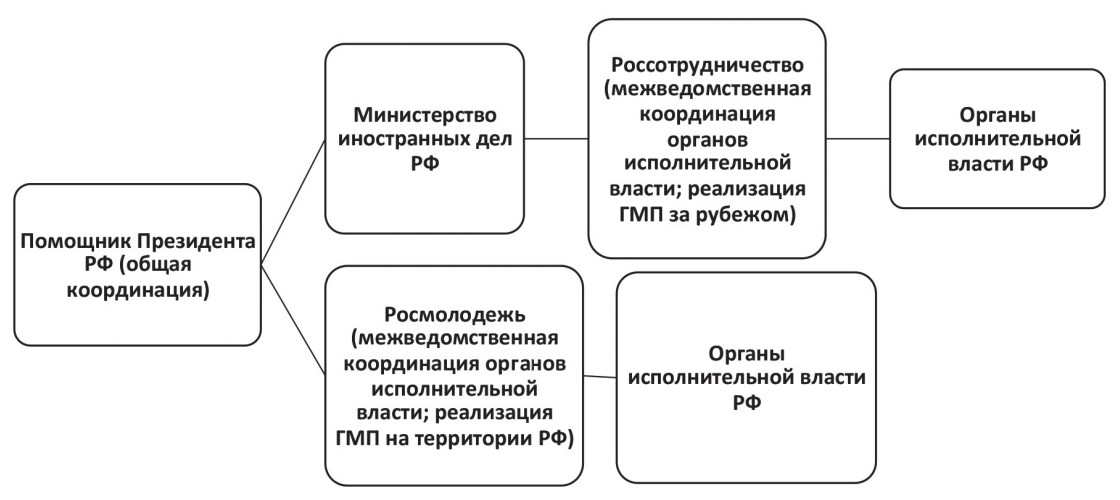

Рисунок 1. Схема институционализации государственной молодежной полиТики

Таким образом, институционализация - это создание нормативно-правового и структурно-иерархического обоснования реализации функций и задач, возложенных на государство, а ГМП - одно из ключевых направлений государственной деятельности, т.к. именно от воспитания молодого поколения зависит будущее государства и человеческой цивилизации.

Работа выполнена в рамках государственного задания ЦИПБ РАН в 2019 году по вопросам исследования проблем обеспечения национальной безопасности Российской Федерации в современных условиях.

\section{Список литературы}

Бадмаева С.В., Леднева С.А., Литвинюк А.А., Кузуб Е.В., Рожков В.Д., Бобков В.Н., Гаврилов М.М., Черных Е.А. 2016. Российская молодежь на рынке труда: экономическая активность и проблемы трудоустройства в мегаполисе: монография. М.: РУСАЙНС. 228 с.

Кочетков А.В. 2004. Конституции зарубежных государств о молодежи и молодежной политике. - Закон и право. № 12. С. 36-40.

Ценностные ориентации российской молодежи и реализация государственной молодежной политики: результаты исследования: монография (под общ. ред. С.В. Чуева). 2017. М.: ИД ГУУ. 131 с. Доступ: https:/guu.ru/wp-content/uploads/ Zak_925_2017-Chuev.pdf (проверено 30.08.2019).

Чирун С.Н. 2009. Молодежнная политика: генезис, состояние, региональная специфика: учебное пособие. Кемерово: Кемеровский государственный институт культуры и искусств. 224 с. Доступ: http://www.bibliorossica.com/book. html?\&currBookId=14258 (проверено 30.08.2019). 
TEMKIN Vladimir Leonidovich, postgraduate student at the Institute of Law and National Security, Russian Presidential Academy of National Economy and Public Administration (RANEPA) (1/21 Dostoevskogo St, Moscow, Russia, 127473; temkinmir@mail.ru)

SINITSYN Igor Mikhailovich, Scientific Secretary of the Center for Security Studies, Russian Academy of Sciences (21b Garibaldi St, Moscow, Russia, 117335; IM_9380752@mail.ru)

\title{
ON THE ISSUE OF INSTITUTIONAL SUPPORT OF THE STATE YOUTH POLICY AND ITS REGULATORY AND LEGAL BASIS IN RUSSIA AND IN THE WORLD
}

\author{
Abstract. The article discusses the issues of ensuring state youth policy in the Russian Federation, briefly shows the \\ experience of foreign states, and outlines the need to adopt the Law on Youth and the importance of institutionalizing the \\ state youth policy. \\ Keywords: state youth policy, institutionalization, youth, legislation, state, society
}

\section{УДК 324}

ОКОРОКОВА Матрена Павловна - кандидат политических наук, доцент кафедры истории, обществознания и политологии исторического факультета Северо-Восточного федерального университета им. М.К. Аммосова (677000, Россия, Республика Саха (Якутия), г. Якутск, ул. Белинского, 58; ovadimka@mail.ru)

ГРИГОРЬЕВ Ньургун Афанасьевич - кандидат политических наук, доцент кафедры истории, обществознания и политологии исторического факультета Северо-Восточного федерального университета им. М.К. Аммосова (677000, Россия, Республика Саха (Якутия), г. Якутск, ул. Белинского, 58; nagrigoriev@mail.ru)

\section{ОБРАЗ ПОЛИТИЧЕСКОГО ЛИДЕРА В ПРЕДСТАВЛЕНИЯХ СТУДЕНЧЕСКОЙ МОЛОДЕЖИ РЕСПУБЛИКИ САХА (ЯКУТИЯ)}

\footnotetext{
Аннотация. В статье проводится анализ данных опросов, связанных с выявлением основных факторов, влияющих на формирование образа политического лидера в представлениях студенческой молодежи Республики Саха (Якутия); исследуются теоретические аспекты политической культуры молодежи и факторы формирования представлений политического лидерства. В процессе эмпирического исследования авторы анализируют структурные компоненты в образах политиков и выявляют основные типы идеального лидера в политических представлениях студенческой молодежи республики.

Ключевые слова: молодежь, политическая культура, политическая социализация, Республика Саха (Якутия), политическое лидерство, образ политика

Y стойчивое развитие политической системы современной России предполагает широкое вовлечение граждан в политический процесс. Согласно классическому подходу американского политолога Д. Истона, активное участие гражданского общества с помощью «импульсов входа» влияет на качество функционирования системы власти. Молодежь является одним из важных и наиболее мобильных компонентов функционирования политического процесса [Easton 1986: 24].
} 